\title{
Attaching a New Understanding to the Patient- Physician Relationship in Family Practice
}

\author{
Darren Thompson, MD, and Paul S. Ciechanowski, MD, MPH
}

Background: As a result of continuity of care with patients and their families, family physicians are uniquely poised to form enduring clinical relationships with their patients. The degree of collaboration in and satisfaction with the patient-provider alliance has been shown to have important implications for treatment outcomes across a range of medical problems. Providing optimal care can require family physicians to appreciate the sequelae of having clinically relevant aspects of past relationships emerge in the health care relationship, both in their patients and in themselves. A conceptual model is essential to assist in recognizing these key aspects.

Methods: A literature search was conducted using MEDLINE. Key words entered were "illness" and "attachment theory." Thirty-five English-only articles appeared from which further relevant references were gathered.

Results: Attachment theory serves as a useful model for highlighting important features of physicianpatient relationships, which can affect treatment outcome in the family practice setting. It posits that everyone has an innate need to form strong attachment bonds to their earliest caregivers. To ensure survival, the child adapts its bonding to the caregiver's attachment style. With time, the maturing person develops a style of relating in subsequent caregiving relationships based on these early, and to some extent later, close relationships. Insecure attachment styles that can develop-dismissing, preoccupied, and fearful-have been shown to affect the clinical relationship and medical treatment outcomes often in important and predictable ways.

Conclusion: Family physicians can more easily adopt an understanding, compassionate, and flexible treatment stance by recognizing patients' unique attachment relationship patterns, thereby improving medical treatment outcome. (J Am Board Fam Pract 2003;16:219-26.)

Family physicians possess unique attitudes, skills, and knowledge that qualify them to provide continuing and comprehensive medical care, health maintenance, and preventive services to all members of the family regardless of sex, age, and type of problem. ${ }^{1}$ In addition to managing $85 \%$ to $90 \%$ of the clinical problems they encounter, ${ }^{2}$ family physicians are also uniquely poised, because of their background and their interactions with a patient's family, to serve as their patient's advocate in such health-related matters as the appropriate use of consultants, health services, and community resources. This multifaceted provider and advocate role, in addition to continuing care, can be extremely satisfying for physicians, but its success is dependent on a good therapeutic alliance. Such a

Submitted, revised 10 June 2002.

From the Department of Psychiatry and Behavioral Sciences (DT, PSC), University of Washington, Seattle. Address reprint requests to Darren Thompson, MD, Box 356560, Department of Psychiatry and Behavioral Sciences, University of Washington, Seattle, WA 98195. relationship can be particularly important when caring for patients with chronic illnesses, in which active and effective collaboration between patient and physician has been shown to be essential to good treatment outcomes. ${ }^{3-6}$

Research has shown that patients are more likely to adhere to treatment and be satisfied with care if they feel their physician is respectful, interested, supportive, and understanding. ${ }^{7}$ To improve clinical outcomes through better adherence and satisfaction, the physician might have to focus on providing a flexible treatment approach based on attunement to patients' fears, their unique perspective of their illness, and their general underlying needs. Being attuned to patients, however, can also require that the physician understand their patients' patterns of interpersonal relationships. The interpersonal style of some patients can be experienced as bothersome or as an obstacle, or it can lead to pejorative labeling, such as "the difficult patient." Attachment theory offers a framework for physicians to better understand and prepare for the 
clinical encounter. By understanding attachment theory, physicians can enjoy and care for a wider range of patients, even those who fall within the extremes of treatment adherence and clinical engagement.

\section{Methods}

A literature search was conducted using MEDLINE. Key words entered were "illness" and "attachment theory." Of the 44 articles that appeared, 35 were written in English, and these articles were reviewed. Further relevant references were obtained from these articles.

\section{Attachment Theory}

Conceptualized in the 1950s by the British psychiatrist John Bowlby, the field of attachment theory has flourished in the past several decades through research exploring interpersonal patterns of response to threatening situations, such as loss, trauma, and illness. Bowlby proposed that the mechanism underlying an infant's tie to a primary caregiver might have emerged as a result of evolutionary pressures. This strikingly strong tie, he suggested, results from a biologically based need for proximity to a care provider that arose through the process of natural selection, the outcome of which is survival through protection from predators. ${ }^{8} \mathrm{Hu}-$ man infants form and maintain primary relationships with caregivers early in life because they are physically and psychologically helpless for so many months after birth. Indeed, their very survival depends on such a relationship. ${ }^{9}$

A child who is consistently responded to will feel worthy of attention and nurturance and will eventually learn to self-regulate distressing emotions. On the other hand, if a child's expression of distress leads to conflict or rejection, the most adaptive strategy is likely to be precocious attempts at controlling the negative emotional experience, either by attempting to inhibit it or by amplifying it. ${ }^{10}$

Such attachment-dependent responses are believed to persist into and throughout adulthood: "Attachment behavior is held to characterize human beings from the cradle to the grave." ${ }^{11}$ In fact, longitudinal studies are confirming the persistence of a person's attachment schemas throughout life. ${ }^{12-14}$ Ill health is likely to activate the attachment system because of distress and perceived vulnerability. Children and adults differ markedly in their responses to unusual or distressing physical symptoms, ${ }^{15}$ and responses to medical illness can be anticipated based on attached patterns. Recent research indicates that outcomes to medical illness in adults differ according to specific attachment patterns. ${ }^{15-20}$ To understand how variations in attachment style play a role in medical illness, it is important to understand the different attachment styles.

\section{Attachment Patterns}

Based on Bowlby's work, as well as research on infants, children, and adults, several attachment classification schemes have been developed, with cross-cultural studies showing remarkable consistency with the theory. ${ }^{21}$ Bartholomew and Horowitz $^{22}$ developed a popular attachment classification system for adults that has four distinct patterns: secure, dismissing, preoccupied, and fearful, with most populations studied being secure. Although it is possible to measure the degree to which a person is characterized by each of these attachment styles, clinically it is often more useful to determine the predominant attachment style. ${ }^{17}$

Insecure attachment strategies develop when primary caregivers have been rejecting, undependable, intrusive, or abusive. In a clinical setting, providers' awareness of insecure attachment styles can be invaluable when assessing and caring for patients. Three types of insecure attachment styles have been described: dismissing, preoccupied, and fearful.

\section{Dismissing Attachment Style}

Patients with dismissing attachment relationships come across as compulsively self-reliant. ${ }^{23}$ This coping mechanism is thought to result from consistent emotional rejection or unavailability by caregivers. To maintain attachment bonds to their caregivers, these patients learned to deactivate $11,23,24$ their attachment needs. Resulting behavior can be seeking distraction from emotions when confronted with stress, downplaying the importance of the problem at hand, ${ }^{22}$ and minimizing the need for others when distressed. Negative emotions, such as anger, are often expressed indirectly and aggressively. ${ }^{25}$ Attachment needs tend to be displaced onto more impersonal aspects of life, such as work, food, or hobbies. These patients might devalue close relationships and maintain su- 
perficial but less overtly problematic social relationships.

Case example. Kim, a 30-year-old married obese woman with type 2 diabetes mellitus, has been your patient for nearly 1 year. Although she appears outwardly friendly and pleasant, she is rather aloof, and you feel that you do not really know her. Clinical communication with her has a superficial quality, and the medical treatment and therapeutic alliance seem insignificant to her and tenuous to you. She comes in every 4 to 8 weeks, often rescheduling visits hours to minutes before her appointment time and occasionally forgetting them altogether. To inquiries about her diabetes, she responds, "everything is great ... no problems." She appears indifferent when asked about her elevated glycosylated hemoglobin levels and urine test strip readings, minimal exercise, persistent weight gain with poor dietary restrictions, and continued cigarette smoking. Although she maintains that taking scheduled medications is "not a big deal" (she is now taking the highest doses of oral bypoglycemic medications), she acknowledges that she has not been taking them regularly, nor has she been monitoring her glucose more than once or twice weekly. She insists she will make the necessary lifestyle changes on ber own, but you cannot belp but feel doubtful and frustrated.

Patients with dismissing attachment styles characteristically appear to their care providers as if they are invulnerable. ${ }^{26}$ They might seem cold and aloof, even when reporting troubling and stressful events. They generally tend not to elaborate on their problems, such as illness, ${ }^{27,28}$ and any descriptions of the impact of illness or other stressors might be minimized. Conversely, they might be overly optimistic without supportive evidence for their optimism. Because they minimize or deny their attachment needs, these patients might actively avoid seeking support from others, downplay their medical symptoms and severity of illness, and remain disengaged in their relationships, including with their family physician.

Problems can ensue when illness begins to interfere with the strategy of self-reliance. Because physicians often experience patients with dismissing attachment as aloof, undemanding, and not problematic, patient care might not be optimal. Family physicians who have a high practice volume might feel relieved by the emotional distance and lack of demands. They might spend less time with the patient, schedule fewer visits, and inquire less into the patient's illness than required by high- quality care. This behavior can confirm the patient's expectations that their attachment needs must be downplayed to continue to receive care, thus leading to poor adherence to medical treatment.

Alternatively, physicians might feel dismissed or rejected when they attempt to care more actively for these patients. The resulting helplessness and anger can lead physicians to either active withdrawal or a more controlling or paternalistic careproviding strategy. For example, physicians might fail entirely to inquire into essential aspects of the patient's illness or, in frustration, might demand that the patient either have regularly scheduled visits or receive no care at all.

\section{Preoccupied Attachment Style}

Patients with a preoccupied attachment style come across as compulsively care-seeking. ${ }^{23}$ Their history tends to be characterized by inconsistent caregiving responses to their needs. ${ }^{29}$ They respond by developing a strategy of hyperactivating ${ }^{1,23,24}$ or exaggerating their expression of attachment needs in the hope of evoking more consistent and predictable support and care from their caregiver. ${ }^{27}$ They might amplify physical symptoms of chronic illness to evoke care from physicians. These patients might develop the belief that only their attachment figures can regulate their emotions and control their problems.

Case example. Carol and her family have been in your practice for several years. She is a 38-year-old woman who schedules visits for an assortment of her own medical concerns and varied symptoms despite being generally bealthy. She makes frequent appointments for berself and for her three children, aged 7 months and 9 and 11 years old, all of whom are also quite healthy. Carol imparts a sense of urgency as she dramatically describes her own or her children's health concerns, even when these concerns are nonthreatening. Because she has little confidence in her own caregiving ability, she immediately seeks your assistance for minor symptoms and matters related to her children's health. This behavior makes you see her as anxious and needy. Despite her desire to be needed as a mother, she seems to be insecure in this role, stating: "I always feel like I am trying too hard." Consistent with her role as a mother, you sense that she is also looking after you. She often comes to the office bearing gifts, and she frequently asks about your bealth and your long-term professional plans, which 
makes it hard for you to put limits to ber frequent bealth care appointments.

Patients who are preoccupied in their attachment relationships often impress physicians as needy and dependent. ${ }^{26}$ They might appear to have little self-confidence and to be unable to trust their own judgment when dealing with even the most straightforward and nonthreatening problems. They might seek care immediately and frequently for relatively minor symptoms and clinical problems and often react strongly when discussing stressful events, such as illness. With worsening illness and mounting stress, these patients are likely to become increasingly dependent on their health care providers and have less confidence in their ability to provide care for themselves or family members. They might not only seek more support but might also appear to be more solicitous of their physicians. Such a strategy is intended to maintain the physician's engagement to ensure continued care and proximity. ${ }^{30}$

Typically, physicians can experience these patients' intense care-seeking needs as burdensome or overbearing. ${ }^{31}$ Common reactions are anger, annoyance, anxiety, confusion, helplessness, and feelings of being overwhelmed. If not contained, these emotions can lead physicians toward excessively controlling interactions. Conversely, because these patients often feel unable to care for themselves, to ensure that the relationship with the physician remains strong, they might try to look after their physician. The physician might have difficulty setting boundaries regarding the frequency or length of visits with someone who is so grateful and attentive. Alternatively, the physician might develop a sense of invulnerability and powerfulness, leading to intrusion on the patient's initiative and competency in caring for themselves. The result often is an inconsistent pattern of care by the physician.

\section{Fearful Attachment Style}

A key feature in patients with a fearful attachment style is their mistrust of both themselves and others when attempting to cope with distress. Most of these patients will have had a history of being mistreated by attachment figures in the past. ${ }^{32,33}$ In such circumstances, primary attachment figures become simultaneously a safe haven and an environmental threat. A characteristic feature of the fearful attachment pattern is the double message of helpseeking and help-rejecting behavior that is elicited when the patient feels threatened by medical illness. A strategy of managing the profound anxiety concerning personal safety might be to exert pressure on the caregiver to deliver more care, care that might ultimately be denied by the patients because of a high level of mistrust in others. ${ }^{30}$

Case example. You see Bill, who is a colleague's patient, while covering weekend call for your clinic. He is 45 years old, divorced, and because of multiple medical problems, retired from a managerial position at a local mine. Your colleague telephones you stating, "I am totally burned out. He constantly demands and demands, but he never takes my help," adding that the clinic staff is also feeling overwhelmed by his frequent telephone calls and angry demands. When you first encounter Bill, your initial impression is of an intelligent, friendly man who you believe would be a pleasure to treat. He relates a lengthy list of unresolved medical concerns in an urgent and angry fashion, bowever. As you inform bim that you have time in this visit to discuss the two most important problems, he interrupts and says loudly, "I knew that you wouldn't be able to help me. ... You're useless!" before slamming the door on bis way out.

Patients with fearful attachment styles struggle to get their needs met when they view all caregiving as potentially threatening and hostile. Various forms of nonadherence to treatment can develop, including failure to take medications as prescribed or missed appointments. In desperation, these patients might demand immediate treatment and make numerous telephone calls and appointments while adopting a dismissive "this won't help" approach to receiving care. The family physician and other clinical staff can begin to feel burned out by the patient's push-pull style, alternating between demanding care with missing appointments and not adhering to treatment.

In response, the family physician might experience a profound sense of incompetence, frustration, hatred, intrusion, or even abuse. It is noteworthy that these are feelings that the patients themselves likely experienced in past or current relationships. If left unchecked, these reactions can lead the physician to withdraw from or retaliate toward the patient, thus confirming the patient's model of caregivers as untrustworthy and threatening.

\section{Clinical Relevance in the Medical Setting}

Attachment theory describes relationship patterns and is not a prescribed treatment approach. Addi- 
tionally, attachment processes constitute only one aspect of human functioning; they do not define persons in all their complexity ${ }^{27}$ or their means of relating in all situations. Nevertheless, this theoretical model can shed much light on patients' relationship and interaction styles in the family practice setting, particularly their responses to the distress of medical illness.

A richer understanding of a patient's attachment style can be a valuable adjunct in providing good clinical care. For example, realizing that the patient with a fearful attachment style can be simultaneously desperate for care and yet unable to trust any care might help the physician be less defensive and take the role of caring for such patients less personally. Similarly, it helps to know that a patient with a dismissing attachment style has unknowingly learned to reject attachment needs as a paradoxical strategy to receive any care at all. Likewise, when experiencing the helplessness engendered by a clinging patient, the physician can attend more objectively to the patient's underlying needs, rather than respond to the most apparent problems, by recognizing the patient's preoccupied attachment patterns. ${ }^{33}$

Of course, physicians also have had varying early caregiving experiences that define their own attachment patterns. As a result, physicians might respond to their patients in ways influenced by their own attachment styles. A study by Dozier and colleagues ${ }^{33}$ provides compelling support for the notion that the attachment pattern of the physician might influence treatment outcome. They found that health care providers who had secure attachment styles were able to hear, attend to, and respond to patients' underlying needs, whereas providers who had insecure attachment styles characteristically responded to the most obvious needs.

An important characteristic of physicians who are more secure is their willingness to intervene in ways that might be uncomfortable for themselves. $^{34,35}$ They neither withdraw nor intrude when they feel pushed away by patients whose attachment style is dismissing. They do not become overly involved, inconsistent, and controlling when they feel overwhelmed by patients whose attachment style is preoccupied. They continue to engage constructively those patients who are fearful in attachment relationships, even in the midst of having to contain aggressive or hostile feelings. The rec- ognition and understanding of attachment patterns can also help the physician provide more readily for the underlying needs of their patients, including medical treatment needs.

\section{Management Strategies for Patients with Insecure Attachment Styles Dismissing Attachment Style}

Enhancing engagement with patients who have dismissing attachment styles requires creativity on the part of the physician. Maunder and Hunter ${ }^{36}$ suggested that improved treatment adherence might be facilitated by strategies which respect the patient's autonomy and need for increased interpersonal distance. A flexible approach, such as accommodating the patient's needs regarding appointment duration and scheduling, might eventually plant in the patient the seeds of a less-fixed view of the interpersonal world. ${ }^{30}$ Accepting the patient's need for compulsive self-reliance while relaying the message that ongoing involvement and responsive care will continue to be provided is essential. The thoughtfully timed introduction of humor, anecdotes, metaphors, and other nonthreatening topics can also enhance engagement. While working with chronically ill patients who have dismissing attachment patterns, clinicians might need to be alert to the possibility of worsening medical illness or complications, given their patients' tendency to underreport symptoms. ${ }^{20} \mathrm{Cli}$ nicians can benefit from using automated appointment-tracking systems, increasing communication through telephone calls, and using proactive contacts, such as mailed appointment reminders, to ensure ongoing engagement with these patients. ${ }^{17}$

\section{Preoccupied Attachment Style}

The physician who is better able to recognize patients' preoccupied attachment patterns might more easily accept a patient's need for both dependence and to have the physician serve as a base from which such patients can develop their own sense of security. Hunter and Maunder ${ }^{30}$ suggested that the aim is to assure that care will be provided before the patient requests it, thereby reinforcing that the patient will receive support regardless of symptom complaints. Such patients can benefit from traditional approaches commonly used for patients with somatization disorder, in which frequent, but brief (eg, 20-minute), appointments are regularly sched- 
uled. ${ }^{20}$ These appointments, which are not contingent on symptoms, have been associated with less need for the patient to develop acute somatic symptoms as a care-eliciting strategy.

To give the patient who has a preoccupied attachment style a sense of security, the physician must be nonintrusive and consistently responsive, while remaining unflappable. By accepting the patient's dependency needs and remaining a consistent source of security, the physician can help the patient develop a greater sense of his or her own initiative, self-trust, and competent self-care, at least in the health care domain. Physicians might need to apply time management skills with these patients to avoid feeling overwhelmed by regularly scheduled visits. Initially, such statements as, "Mrs. Jones, we have 20 minutes to spend together today. What problem would you like to focus on?" help provide structure to the clinical setting. It is crucial, however, that the physician remain responsive to all types of patient concerns, somatic or otherwise.

\section{Fearful Attachment Style}

Patients who have a fearful attachment style engage in health care relationships as long as they are not interpersonally threatening. When caring for these patients, it can be helpful for family physicians to accept patients as they are, to acknowledge the negative emotions that might arise when interacting with these patients, and to continue to provide active treatment. These behaviors imply that the physician is responsive, sympathetic, and willing to take the patient's problems seriously. By resisting the urge to withdraw, the family physician challenges the patient's view of caregivers as threatening. A major challenge for the physician is to observe his or her own personal limits and not blame the patient or conclude that the patient's distress is too great to bear. As rapport and trust build, the patient might be better able to explore the enormous bind he or she faces between seeking help and rejecting help.

When working with hospitalized patients who have a fearful attachment style, it is useful for the physician to clarify realistic expectations about treatment ${ }^{30}$ while helping the patient contain negative emotions. The physician can acknowledge and validate the difficulties these patients face in the treatment setting and, if necessary, set limits for acceptable expressions of anger. In the outpatient setting, some patients might benefit mutually from having several clinic providers provide care in a coordinated fashion, without an emphasis on care by a single provider, although the patient might eventually learn to trust a single provider. ${ }^{20}$ The clinic rather than an individual clinician can become the provider ${ }^{17}$ and thus be less threatening to the patient. Team care with physician, nurse, and mental health professionals might provide the optimal treatment strategy for patients with fearful attachment.

Occasionally, it might be necessary to refer patients with insecure attachment styles to consultant nurses, nurse case managers, social workers, psychologists, psychiatrists, or other clinicians skilled in psychological medicine. The goal would be to assess the patient's style of interacting in the health care setting and to develop a plan to enhance patient-provider contact or at least to maintain contact between the patient and the clinic. Psychological consultation could also serve to assess the patient, the patient's family, and the patient's social network, while ruling out other possible problems, such as substance abuse, anxiety disorders, depression, and personality disorders. Such providers could serve as temporary consultants or provide a longer term therapeutic relationship that is adjunctive to and collaborative with the family physician.

\section{Conclusion}

A deeper understanding of the role of attachment within the patient-provider relationship can lead to better patient care and enrich the family physician's clinical experience. By recognizing that patients' illness behavior and providers' responses to them can be manifestations of attachment patterns, the physician can be more empathic to patients who might otherwise be viewed as hateful, demanding, or difficult. Most importantly, attachment theory can help family physicians understand that patients commonly complain of medical and psychological symptoms as an expression of an underlying relationship need, a need they might not be able to express verbally or consciously.

"[The patient's] need of love, concern, sympathy and, above all, to be taken seriously must be accepted and to some extent gratified in the treatment before he can be expected to experiment with methods other than his illness of ob- 
taining the affection and care for which he is craving." -Michael Balint ${ }^{37}$

The authors wish to thank Mark Sullivan, MD, $\mathrm{PhD}$, Wayne Katon, MD, Larry Mauksch, MEd, Sofia Bayfield, MD, and Elizabeth Dixon, MD, for their scientific input and review of the manuscript. The primary author would also like to thank Simone Thompson and Ann De Lancey, $\mathrm{PhD}$, for their wisdom and inspiration.

\section{References}

1. Facts about AAFP. AAFP reprint no. 300. Kansas City, Mo. The Academy, 1993. Available at: http:// www.aafp.org/x7637.xml. Accessed May 1999.

2. A manpower policy for primary health care: report of a study. Institute of Medicine, Division of Health Manpower and Resources Development. Washington, DC: National Academy of Sciences, 1978:30. (IOM publication no. 78-02.)

3. Stewart MA. Effective physician-patient communication and health outcomes: a review. CMAJ 1995; 152:1423-33.

4. Sherbourne CD, Hays RD, Ordway L, DiMatteo MR, Kravitz RL. Antecedents of adherence to medical recommendations: results from the Medical Outcomes Study. J Behav Med 1992;15:447-68.

5. Hall JA, Roter DL, Datz NR. Meta-analysis of correlates of provider behavior in medical encounters. Med Care 1988;26:657-75.

6. Anderson RM, Funnel MM, Butler PM, Arnold MS, Fitzgerald JT, Feste CC. Patient empowerment. Results of a randomized controlled trial. Diabetes Care 1995;18:943-9.

7. Miller WR, Rollnick S. Motivational interviewing: preparing people to change addictive behavior. New York: Guilford, 1991.

8. Cassidy J. The nature of the child's ties. In: Cassidy J, Shaver P, editors. Handbook of attachment: theory, research, and clinical applications. New York: Guilford, 1999.

9. Slade A. The development and organization of attachment: implications for psychoanalysis. J Am Psychoanal Assoc 2000;48:1147-74.

10. Sroufe LA. An organizational perspective on the self. In: Cicchetti D, Beeghly $M$, editors. The self in transition: infancy to childhood. Chicago: University of Chicago Press, 1990.

11. Bowlby J. Attachment. New York: Basic Books, 1969. Attachment and loss, vol 1.

12. Grossman KE, Grossman K. Attachment quality as an organizer of emotional and behavioral responses in a longitudinal perspective. In: Parkes CM, Stevenson-Hinde J, Marris P, editors. Attachment across the life cycle. London: Routledge, 1991.

13. Hamilton CE. Continuity and discontinuity of at- tachment from infancy through adolescence. Child Dev 2000;71:690-4.

14. Waters E, Merrick S, Treboux D, Crowell J, Albersheim L. Attachment security in infancy and early adulthood: a twenty-year longitudinal study. Child Dev 2000;71:684-9.

15. Feeney JA. Implications of attachment style for patterns of health and illness. Child Care Health Dev 2000;26:277-88.

16. Feeney JA, Ryan SM. Attachment style and affect regulation: relationships with health behavior and family experiences of illness in a student sample. Health Psychol 1994;13:334-45.

17. Ciechanowski PS, Walker EA, Katon WJ, Russo JE. Attachment theory: A model for health care utilization and somatization. Psychosom Med, in press.

18. Ciechanowski PS, Katon WJ, Russo JE, Walker EA. The patient-provider relationship: attachment theory and adherence to treatment in diabetes. Am J Psychiatry 2001;158:29-35.

19. Stuart S, Noyes R Jr. Attachment and interpersonal communication in somatization. Psychosomatics 1999; 40:34-43.

20. Ciechanowski PS, Katon WJ, Russo JE, DwightJohnson MM. Association of attachment style to lifetime medically unexplained symptoms in patients with hepatitis C. Psychosomatics 2002;43:206-12.

21. Van Ijzendoorn MH, Sagi A. Cross-cultural patterns of attachment. Universal and contextual dimensions. In: Cassidy J, Shaver PR, editors. Handbook of attachment: theory, research, and clinical applications. New York: Guilford, 1999.

22. Bartholomew K, Horowitz LM. Attachment styles among young adults: a test of a four-category model. J Pers Soc Psychol 1991;61:226-44.

23. Bowlby J. Loss: sadness and depression.. New York: Basic Books, 1980. Attachment and loss, vol 3.

24. Bowlby J. Separation: anxiety and anger. New York: Basic Books, 1973. Attachment and loss, vol 2.

25. Main M, Weston DR. The quality of the toddler's relationship to mother and to father: related to conflict behavior and the readiness to establish new relationships. Child Dev 1981;52:932-40.

26. Dozier M. Attachment organization and treatment use for adults with serious psychopathological disorders. Dev Psychopathol 1990;2:47-60.

27. Slade A. Attachment theory and research: implications for the theory and practice of individual psychotherapy with adults. In: Cassidy J, Shavers PR, editors. Handbook of attachment: theory, research, and clinical applications. New York: Guilford, 1999.

28. Main M, Kaplan N, Cassidy J. Security in infancy, childhood, and adulthood: A move to the level of representation. In: Bretherton I, Waters E, editors. Growing points of attachment theory and research. Monogr Soc Res Child Dev 1985;50(1-2:serial no.209):66-104.

29. Ainsworth MD, Blehar MC, Waters E, Wall S. Pat- 
terns of attachment: a psychological study of the strange situation. Hillsdale, NJ: Lawrence Erlbaum 1978.

30. Hunter JJ, Maunder RG. Using attachment theory to understand illness behavior. Gen Hosp Psychiatry 2001;23:177-82.

31. Carlson V, Cicchetti D, Barnett D, Braunwald K. Finding order in disorganization. In: Cicchetti D, Carlson VK, editors. Child maltreatment: theory and research on the causes and consequences of child abuse and neglect. New York: Cambridge University Press, 1989.

32. Lyons-Ruth K. Attachment relationships among children with aggressive behavior problems: the role of disorganized early attachment problems. J Consult Clin Psychol 1996;64:64-73.
33. Dozier M, Cue KL, Barnett L. Clinicians as caregivers: role of attachment organization in treatment. J Consult Clin Psychol 1994;62:793-800.

34. Cashdan S. Stage two: projective identification. In: Object relations therapy: using the relationship. New York: WW Norton, 1988.

35. Marshall RJ, Marshall SV. The transference-countertransference matrix: emotional-cognitive dialogue in psychotherapy, psychoanalysis, and supervision. New York: Columbia University Press, 1988.

36. Maunder RG, Hunter JJ. Attachment and psychosomatic medicine: developmental contributions to stress and disease. Psychosom Med 2001;63:556-67.

37. Balint M. The doctor, his patient, and the illness. London: Pitman Medical, 1964. 